Bol. Acad. perú. leng. 50. 2010 (129-166)

\title{
VISIÓN ACHUAL DEL PARAÍSO
}

\section{UNE VISION ACHUAL DU PARADIS}

\section{ACHUAR VISION OF THE PARADISE}

\author{
Héctor Gómez Navarro \\ Universidad de Oviedo ${ }^{1}$
}

\section{Resumen:}

Este artículo presenta una traducción y estudio de los mitos paradisíacos del pueblo achual, una comunidad indígena peruana. Los textos hablan acerca de la pérdida de la condición edénica y el origen del pueblo y las instituciones achual. El análisis y estudio pretenden ofrecer una mirada filológico-antropológica sobre estos mitos.

\section{Résumé:}

Cet article présente une traduction et une étude des mythes paradisiaques du peuple Achual, une communauté autochtone du Pérou. Les textes traitent de la perte de l'état édénique et de l'origine du peuple et des institutions achual. L'analyse et l'étude veulent apporter un regard philologique -anthropologique sur ces mythes.

1 Becario predoctoral "Severo Ochoa" subvencionado por el Principado de Asturias a través de su Plan de Ciencia, Tecnología e Innovación. 


\section{Abstract:}

This article shows a translation and analysis of the Native Peruvian's myths. The texts talk about the loss of the endemic condition and the origin of Achual's people and institutions. The analysis and study try to provide a philological and anthropological look about these myths.

\section{Palabras clave:}

Mitos; pueblos amerindios; achual; jívaro; cosmogonía.

Mots clés:

Mythes; peuples amérindiens; Achual; Jivaro; cosmogonie.

Key words:

Myths; Amerindian people; Achual; Jibaro; cosmogony.

Fecha de recepción:

$11 / 09 / 2010$

Fechade aceptación:

$30 / 09 / 2010$

Son muchos los estudios que han prestado atención a la visión de los europeos sobre los pueblos indígenas; otros, en especial en el s. XX, atendieron a la visión que los pueblos originarios tuvieron de los conquistadores, pero son pocos los estudios sobre la imagen que de sí mismos tenían los indígenas antes de la llegada del hombre europeo. El presente trabajo se ocupa de la idea de la Edad de Oro entre los achual, uno de los pueblos que habitaban las tierras que, para los europeos, tenían las características edénicas; es, por tanto, un análisis de la visión del paraíso desde el paraíso. La Edad de Oro, según la ha definido Mircea Eliade, es aquella en la que se disfruta de inmortalidad, libertad, espontaneidad, ${ }^{2} 3$ posibilidad de ascender al cielo y encuentro fácil con los dioses; amistad con los animales y conocimiento de su lengua. ${ }^{3}$

2 Libertad y espontaneidad referidas a que el ser humano no está sujeto a las restricciones físicas, temporales ni sociales de este mundo,

3 ELIADE, Mircea, Mitos, sueños y misterios. Madrid, Kairós 2001, pág. 76. 


\section{Descripción del pueblo achual}

El pueblo achual (también llamado achuar) es un grupo humano de la selva amazónica de Perú. Sus territorios se extienden por el Departamento de Loreto, en el Norte del país, entre los ríos Morona y Tigre. En el censo nacional de 1993 se registraron 4,719 achuales. ${ }^{4}$ Son un grupo minoritario de la etnia jíbara ${ }^{5}$ y su idioma, el achuar-shiwiar, pertenece al tronco lingüístico jíbaro.

Las primeras noticias que tenemos de los achual se remontan al reinado de Túpac Inca Yupanqui (1471-1493), quien lanzó dos expediciones de conquista contra el pueblo jíbaro de los bracamoros, hoy desparecido. Más tarde, Atahualpa (1532) también enviaría tropas contra las poblaciones jíbaras. Tras la conquista española del Tahuantinsuyo en 1532-33, se producirá la invasión de las tierras del pueblo bracamoro en 1542, fundándose en ellas (1549) las poblaciones de Logroño y Sevilla del Oro. En 1557, Juan Salinas de Loyola entra en la zona, fundando Santiago de Las Montañas, y dos años más tarde los pueblos shuara y achual reúnen a 20000 guerreros que destruyen las poblaciones españolas.

En 1682, el padre jesuita Lucero inicia en la región una expedición sin armas ni apoyo militar, fundando la misión Naranjos de los Jíbaros. En 1767, se sabe que funcionaban en la zona, además de esta misión, las reducciones Nuestra Señora de los Dolores de Muratos y Sagrado Corazón de los Jíbaros. Tras la expulsión de la Compañía de Jesús, los achual viven una etapa de relativa independencia hasta que, a finales del s. XIX, el auge de la industria del caucho lleva al Estado peruano a permitir el establecimiento de industrias caucheras en tierras amazónicas. La dura resistencia de los achual da paso a una relación comercial, según la cual el caucho en bruto era entregado por los indígenas a cambio de armas de

4 BRACK EGG, Antonio y YANEZ, Carlos (Coordinadores). Amazonia peruana: Comunidades indígenas, conocimientos y tierras tituladas. Atlas y base de datos. GEF / PNUD/ ONUPS. Edición en CD-ROM, 1998.

5 Esta etnia se compone en el Perú de los pueblos achual, candoshi, huambisa, jibaro y aguaruna, el más numeroso, además del desaparecido pueblo bracamoro. En Ecuador habitan los shuara.

Bol. Acad. peru. leng. 50(50), 2010 
fuego, herramientas y telas. Hasta 1950 este sistema será utilizado también por los exportadores de otras materias primas, produciéndose entonces el asentamiento permanente de industriales y comerciantes blancos y mestizos en los territorios achual.

La estructura de población tradicional de los achuales se basa en pequeños centros, que pueden ser abandonados y recuperados según la escasez o abundancia de recursos. Tal estructura se vio alterada, además de en la época colonial, con la llegada en 1964 de integrantes del Instituto Lingüístico de Verano, ${ }^{6}$ que para realizar mejor su labor concentran a los achuales en grandes asentamientos que en 1982, al salir aquellos de la región, son abandonados, retomándose entonces el sistema tradicional (Brack Egg, 1998).

Respecto a la organización social de los achuales, hay opiniones contradictorias. Gerhard Fast, estudioso perteneciente al ILV, afirma que los achuales viven en aldeas cuyo jefe es un varón. Este accede a la jefatura local por dos vías: en tiempos de guerra, por ser el mejor guerrero o estratega; en tiempos de paz, por ser el hombre con más hijas casadas. Esto se debería a que los achuales tienen residencia matrilocal: el marido va a vivir al lugar de residencia de la familia de la esposa, quedando obligado a prestarle asistencia a sus suegros, por lo que un varón con muchas hijas casadas tendría en su aldea a muchos hombres a su servicio, y por tanto más influencia política. ${ }^{7}$

Esta teoría se contradice con los testimonios de los achuales, que incluye el propio Fast en su edición, y con el esquema social que se trasluce en los mitos y leyendas de este pueblo. Por ejemplo, en uno de los relatos míticos que nos ocupan, ${ }^{8}$ referido al héroe cultural Nayap, tanto éste como su competidor Tsuná quieren llevar a las mujeres que

6 Summer Institute of Linguistics, organismo de origen norteamericano dedicado al estudio y enseñanza de lenguas indígenas y a la predicación de la doctrina cristiana protestante. En adelante, ILV.

7 FAST, Gerhard, Cuentos folklóricos de los achual, Lima, ILV, 1978, págs. 1-3.

8 CHUMAP PIRISÁN, Mariano, «Nayap (La tijera chupa)», en FAST, Gerhard, Cuentos... págs. 99-107. 
desean como esposas a sus propias casas, en lugar de trasladarse a las de ellas. En los testimonios directos ${ }^{9}$ se observa que, al hablar de los tabúes relacionados con el nacimiento de los niños y sus primeros cuidados, es la madre del marido quien ayuda a la crianza, lo que implica una residencia patrilocal.

Por otra parte, Antonio Brack Egg y Carlos Yáñez afirman que los achuales viven en aldeas de unos 150 individuos de media. El jefe en tiempos de paz sería un varón que adquiere influencia política casándose con las hijas de un hombre poderoso, quien le daría apoyo y prestigio. La poligamia no estaría reservada a los jefes, pero tampoco sería obligada para los varones del "pueblo llano", dándose casos de matrimonios monógamos. La residencia sería patrilocal, lo que implica una organización patriarcal, ${ }^{10}$ sistema que, con ciertas reservas, puede decirse que es el propio de este pueblo. ${ }^{11}$

Existe entre los achuales la institución del levirato, esto es, la obligación de la mujer viuda de casarse con un hermano del marido muerto. No obstante, es posible que una mujer viuda pueda casarse con otro varón si este paga una dote a los cuñados de ella, que de esta manera renunciarían a sus derechos matrimoniales. ${ }^{12} \mathrm{Al}$ parecer, esta institución es una fuente continua de conflictos entre las comunidades achual.

En lo que respecta a los medios de subsistencia, el pueblo achual tiene una dedicación mixta a la caza, pesca y recolección, por un lado

9 CHUMAP PIRISÁN, Mariano, «El nacimiento de un niño», y NANTIP, Tsanim, «Cómo mueren nuestros hijos», en FAST, Gerhard, Cuentos... págs. 134-139 y 140-147. respectivamente.

10 En el $75 \%$ de los casos, si hay residencia patrilocal hay patriarcado. Véase MURDOCK, George Peter, «Ethnographic Atlas: a summary», en Ethnology, $\mathrm{n}^{\circ}$ 6, volumen 2, University of Pittsburgh, 1967, págs. 108-236.

11 La estructura patriarcal también puede deducise de los estudios de José Arnalot. Véase ARNALOT, José, Lo que los achuar me han enseñado, Quito, Abya-Yala, 2007, págs. 209213.

12 CHUMAP PIRISÁN, Mariano, «Nuva nuvatkatin (el matrimonio)», en FAST, Gerhard, Cuentos... págs. 124-133. 
y, por otro, al cultivo de pequeños huertos. ${ }^{13}$ También hay actividad maderera, aunque está controlada por "patrones" blancos o mestizos.

\section{Metodología. La presente traducción}

El presente trabajo se basa en varios relatos recogidos en el libro de Gerhard Fast, Cuentos folklóricos de los achual. En él recopila textos referidos a los mitos y leyendas de este pueblo y otros, a sus costumbres. La edición es bilingüe, en español y achuar-shiwiar, y presenta varios problemas. Por una parte, la versión española contiene incongruencias y errores, por lo que en una primera fase de traducción hemos procurado eliminarlos. En un segundo momento, hemos adaptado el texto original para adecuarlo a la estructura narrativa de la lengua española y eliminar las barreras culturales que podrían hacer el texto incomprensible a lectores no familiarizados con el pueblo achual; también hemos ampliado pasajes que pudieran resultar oscuros añadiendo información complementaria extraída de fuentes acreditadas, siempre indicada en nota al pie y sin traicionar el contenido de los textos. Por otra parte, la versión ofrecida por Fast es una traducción frase a frase de los relatos. Esto, si bien es una virtud en el texto «Pangki (La anaconda)» de Roberto Jimpikit Saserat, en tanto que se trata de una creación escrita y con voluntad de estilo, es un inconveniente en los demás, puesto que son testimonios grabados y transcritos o bien tomados al dictado, con lo que se reproducen las reiteraciones y desórdenes propios del lenguaje conversacional.

Para la presente traducción hemos seleccionado los textos referidos a la idea del paraíso y la Edad de Oro, que son, por el orden que les hemos dado en la traducción, los siguientes: «Suva ipiakjai (La huito mujer y la achiote mujer)», de Remigio Dahua Carmina; «Nayap (La tijera chupa)», de Mariano Chumap Pirisán; «Nujang (La creciente)», de Vashikat Pisango Sande; «Nujang (la creciente)»(sic) de Remigio Dahua Carmina y «Pangki

13 Los principales cultivos del pueblo achual son la yuca, la papaya, la piña, el frijol, el arroz, al achiote y el maíz. Véase BRACK EGG, Antonio y YAÑEZ, Carlos (Coordinadores). Amazonía peruana...Edición en CD-ROM, y FAST, Gerhard, Cuentas..., págs. 1-3. 
(La anaconda)» de Roberto Jimpikit Saserat. La ordenación que hemos dado a los relatos no coincide con la de Fast y responde a motivos de coherencia mitológica y continuidad entre los textos. Los tres últimos textos citados, puesto que refieren distintas versiones del mismo mito, han sido unidos.

\section{Los relatos. Historia y temática}

Los relatos fueron recogidos por un equipo del ILV dirigido por Gerhard Fast en 1976. Pese a que esta fecha es reciente, los textos seleccionados conservan un alto grado de pureza debido a factores históricos: los achuales no llegaron a ser dominados por el Imperio incásico ni por el español y la República de Perú sólo ha ejercido un control nominal sobre sus tierras; y culturales, pues el carácter independiente de los achuales, sumado a su necesidad de defenderse frente a conquistadores muy poderosos, conlleva una importante reticencia hacia elementos culturales externos. Además, el mantenimiento del sistema de creencias originario, sólo influido superficialmente por ideas cristianas, ha permitido que los textos permanezcan en la cultura achual como mitos, no como leyendas ni cuentos populares, más proclives al mestizaje y la deformación. Es por esto que aparecen en los relatos conflictos problemática de la imposición del sistema patriarcal, tipo de relaciones con lo sagradoque remiten psicológicamente a la transición de la sociedad nómada de cazadoresrecolectores a la sociedad sedentaria de ganaderos-agricultores, que en buena parte del mundo se produjo a lo largo de la era neolítica pero que en el pueblo achual sigue en desarrollo.

Respecto a la temática de los relatos, en ellos se narran los episodios que dieron lugar a la pérdida de la condición edénica y la inauguración del actual tiempo cosmológico, caracterizado por la presencia del trabajo, la muerte y el paso del tiempo cronológico. El primer texto cuenta cómo dos mujeres que buscan marido son engañadas por dos hombres y ayudadas o despreciadas por otros; el primer engaño viene de un hombre que será transformado en ardilla como castigo por la siguiente acción: promete matrimonio a las mujeres, aunque cuando éstas cosechan todo 
el maíz de su huerto mágico, él rompe su compromiso y las encierra, luego ellas son liberadas por una coalición de personajes que serán, después, convertidos en diversos animales de la selva. Tras este episodio se encuentran con Nayap, héroe cultural de todos los pueblos jíbaros, quien desea sinceramente el matrimonio con las mujeres. Estas son, no obstante, engañadas por Tsuná, que les hace tomar el camino a su propia casa y mantiene relaciones sexuales con ellas. Cuando las mujeres descubren la verdadera identidad de Tsuná lo abandonan, pero quedan marcadas por el desagradable olor procedente de una infección ocular del hombre. Debido a esta marca son despreciadas por otros hombres, y aunque Nayap les ofrece recuperar su virginidad bañándose en el río, ellas, debido a la vergüenza que sienten, se convierten en árboles y premian o castigan a los otros personajes, según hubiera sido su comportamiento, convirtiéndolos en distintos seres de la naturaleza. A consecuencia de las injusticias cometidas contra las dos mujeres, se produce la pérdida de ciertas características paradisíacas, aunque todavía existen otras.

El segundo texto cuenta cómo Nayap, triste por su soledad, eleva una plegaria que es respondida cuando una estrella cae del cielo y se transforma en Nuncui, mujer sobrenatural que restablece algunas características paradisíacas y se convierte en su compañera. Cuando la pareja tiene un hijo, Nuncui establece las normas para la crianza, y al ser desobedecidas por una familia, el niño muere. Nuncui regresa al cielo provocando la pérdida de las características paradisíacas que había restablecido y Nayap, siguiendo a su mujer, se convierte en pájaro.

El tercer texto cuenta la historia de un hombre que libera una anaconda atrapada en un espinar. Por la noche, una hermosa mujer aparece en su casa y le revela que es la serpiente que había salvado y a la vez una tsunki, un ser sobrenatural que habita en el río. Tras vencer las reticencias de él, la pareja se casa y habita durante un tiempo bajo el río en la ciudad de los tsunki, para después regresar al pueblo del hombre, en tierra. Allí, la mujer se convierte en anaconda por el día, y guardada entonces en una cesta, con advertencia expresa del hombre de que nadie debe abrirla. Desobedecida la orden por su madre, que además golpea a la serpiente, la tsunki desencadena el Diluvio Universal, salvándose únicamente, por intercesión de su marido -que regresa al pueblo bajo el 
río- un hombre que se sube a un árbol de huito. Cuando las aguas regresan a su cauce, el sobreviviente se encuentra solo, pero de manera inexplicable aparece comida preparada. Con una artimaña, el hombre descubre que la comida es cocinada por un grupo de mujeres que tras el trabajo se convierten en loras; él las atrapa en distintos lugares, las convierte en sus esposas haciendo, además, que pierdan su capacidad de transfiguración. Con esto, desaparecen todas las características paradisíacas y se inicia el actual tiempo cosmológico.

\section{Textos}

1. Historia de Nayap y las mujeres-árbol, que cuenta la primera Edad de Oro, cuando los árboles y los animales eran como las personas, y cómo se convirtieron en lo que ahora son.

Los árboles que ahora se llaman el huito y el achiote al principio eran mujeres. ${ }^{14}$ Así cuentan nuestros antepasados. Era el tiempo en que animales y árboles eran como las personas, y todos compartían una misma lengua. La huito, como era mujer, andaba por el mundo buscando un compañero para casarse. La ardilla por entonces era un hombre fuerte, bien parecido, y la engañó diciendo:

- Ven, yo me casaré contigo. Tengo cuatro plantas de maíz en mi huerto; coséchalo y máscalo para que se pueda cocinar, y luego vamos a comer.

Entonces la huito y la achiote se fueron a cosechar el maíz. ${ }^{15}$ Viendo las cuatro plantas, cogieron todas las mazorcas y echándolas en su

14 Huito: Genipa americana. Achiote: Bixa orellana. Véase FARR, Ellen; LEUSIINK, Jan; STAFLEU, Frans, Index Nominum Genicorum (Plantarum), Utrecht, Bohn, Scheltema \&. Holkema, 1979, págs. 708 y 206, respectivamente.

15 Las dos mujeres permanecen juntas a pesar de que la oferta de matrimonio parece ser sólo para la huito porque son hermanas, como se señalará más adelante, y en este mito rige la estructura achual del matrimonio poligínico sororal, esto es, la unión de un hombre con varias mujeres hermanas entre sí, 
canasta regresaron a la casa de la ardilla. Al entrar en el monte, las mazorcas empezaron a multiplicarse y la canasta se llenó de maíz ${ }^{16}$ hasta casi reventar la cesta.

Cuando vio esto, la ardilla se enojó. Aunque no había advertido a las mujeres que su maíz aumentaba al salir del huerto, les dijo:

- ¿Por qué han hecho esto? ¿'Les he mandado yo que se lleven todas las mazorcas que tenían mis plantas?

Y así, aunque había prometido que se casaría con la huito, cuando las dos mujeres estaban dormidas hizo un enrejado de cañas de bambú. Con él las encerró, y allí las dejó sufriendo.

La pava del monte, ${ }^{17}$ que en ese momento venía de visita, vio el tormento de las mujeres y trató de cortar el bambú con su hacha. Era pequeña su herramienta y no podía hacerlo. Llamando al trompetero ${ }^{18}$ le dijo:

- Trompetero, tú tienes las piernas mucho más largas. Ve y avisa a mi cuñado el paujil, ${ }^{19}$ dile que aquí hay mujeres que están sufriendo. Su hacha es grande, y cortando el bambú las vamos a liberar.

16 Es característica de la Edad de Oro de todas las tradiciones mitológicas la facilidad para obtener el sustento sin trabajar, a través de una naturaleza generosa o de la consecución o multiplicación de los alimentos de forma mágica. Véase ELIADE, Mircea, Mitos..., pág. 43.

17 Pava del monte: Ave del género Penelope. Véase CENDERO, Luis, Zoología hispanoamericana: vertebrados, Austin, UTAA, 1972, pág. 716.

18 Trompetero: Planta, brugmansia arbórea, especie de datura (Véase FARR, Ellen; LEUSIINK, Jan; STAFLEU, Frans, Index... págs. 241 y 497) en la que se encuentran alcaloides con poderes alucinógenos muy apreciados para proporcionar visiones dentro de los usos chamánicos. Si el trompetero llama a alguien, (al paujil, en este caso) se entiende dentro de la cultura de los achual que es un tipo de llamada sobrenatural. Véase POLÍA, Mario, La sangre del cóndor, Lima, FECP, 2001, págs. 29-51.

19 Paujil: Ave del género Crax, algo mayor que la pava del monte. ELLIOT, Jorge, La diversidad bilógica de los Andes tropicales, Lima, ITDG, 2001, pág. 11. 
Cuando llegó el paujil preguntó a las mujeres por qué se encontraban en aquella condición, y ellas le respondieron llorando que la ardilla las había encerrado.

- Quédense quietas. - les dijo, y cortando por todos lados el bambú tiró el enrejado.

- Ay, ¡Cuánto hemos sufrido!- dijeron ellas al levantarse.

Como la ardilla, al marcharse, se había llevado su casa levantando del suelo los horcones, de nuevo las mujeres andaban por el mundo, durmiendo a la intemperie. Yéndose a otra tierra llegaron donde vivía un hombre que se llamaba Nayap. Cuando llegaron, él venía por una trocha ${ }^{20}$ de la selva, armado con su cerbatana para cazar pájaros. Al encontrarlas, él preguntó:

- ¿A qué han venido?

- Hemos venido a verte. - respondieron ellas.

- He dejado a mi mamá en la casa, -respondió él entonces.- Vayan allá, adelántense mientras yo voy a virotear ${ }^{21}$ animales con mi cerbatana. Mi mamá es viejita, la he dejado mascando maíz para cocinar. Vayan y ayúdenla. En la trocha que lleva a mi casa están metidas las plumas de la cola de un guacamayo. ${ }^{22}$ Vayan por allá. El compadre Tsuná tiene en el camino a su casa plumas de chicua. ${ }^{23}$ Por donde vean plumas de chicua no vayan.

Cuando dijo esto también Tsuná lo oyó, y corriendo fue a poner en su camino las plumas de guacamayo. Y al llegar las mujeres fueron

20 Corredor de la selva despejado de vegetación.

21 Cazar anímales con la cerbatana; los virotes son sus dardos.

22 El guacamayo es, en distintas culturas indígenas, un enviado de los dioses. Con esta referencia se sugiere el carácter de ser luminoso de Nayap, así como su facilidad para contactar con entidades sobrenaturales. Véase GALEANO, Eduardo, Memoria del fuego 1: Los nacimientos. Madrid, Siglo Veintiuno Editores, 2003 [1982], págs. 3- 53.

23 La chicua es un ave nocturna semejante a un milano. Dentro de la cultura achual, puede set el enviado de un brujo malero (dedicado a la magia negra), por lo que el carácter maligno de Tsuná es ya sugerido a través de esta referencia. 
por esa trocha. Así llegaron a la casa donde estaba la madre de Tsuná, y le dijeron:

- Tu hijo nos dijo "Mi mamá está mascando maíz. Ayúdenla”. ¿Ya lo ha terminado?

- Sí, ya lo terminé, -dijo ella.

Entonces, la huito dijo a su hermana:

- Él nos dijo "Mi mamá está mascando maíz para llenar una olla grande". ¿De veras lo habrá terminado?

- Mi hijo no va a tardar. Vendrá pronto. - dijo la mamá de Tsuná, para que las mujeres se quedasen con ella.

Y las mujeres se quedaron esperando. Ellas querían que Nayap regresase pronto porque deseaban casarse con él, pero se hizo de noche sin que apareciese. Entonces la huito mujer dijo:

- Mamá, yo voy a regresar por el camino para encontrarme con tu hijo.

- No, solito va a venir- respondió la madre, y así quedaron esperando.

Cuando estuvo completamente oscuro llegó Tsuná. Esperó hasta la noche porque sus ojos estaban llenos de pus, y no quería que las mujeres lo viesen. ${ }^{24}$ Cuando él llegó, las mujeres creyeron que era Nayap, y porque querían casarse con él trataron de agradarle. Así, Tsuná y la huito mujer estuvieron jugando hasta la medianoche. ${ }^{25}$ Por eso cuando amaneció él todavía estaba durmiendo. Con la luz se notaba que los ojos de Tsuná estaban llenos de pus, por lo que su madre se levantó y le dijo:

- Has jugado tanto con la mujer que te has quedado dormido. ¿Tanto tiempo quieres dormir?

24 El aspecto purulento de los ojos de Tsuná es resultado de una infección relativamente frecuente en la selva. En un nivel simbólico, sugiere la perspectiva enfermiza y sesgada de Tsuná.

25 Obsérvese que los achual se refieren a las relaciones sexuales en términos de juego. 
Entonces Tsuná salió corriendo, diciendo que iba a buscar comida. Con la prisa se dejó su alforja. Entrando en el monte, pidió a su madre que se la llevara.

- Mamacita, yo voy corriendo a dársela, -dijo la huito.

Pero la madre de Tsuná, temiendo que las mujeres viesen a su hijo, y por su aspecto o por su engaño lo abandonasen, respondió:

- No, yo sólita voy a dársela.

Y cuando la madre se había ido, una de ellas dijo:

- ¿Por qué estoy oliendo así? Ayer estuvimos con el hombre que vimos tan buen mozo. Pero, ¡apesta tanto!-La mujer no sabían que aquel era el hedor de los ojos purulentos de Tsuná. Añadió después- Vamos a regresar otra vez por el camino.

Entonces, yendo por la trocha, vieron en la senda las plumas del guacamayo y por allá entraron. Cuando estaban yendo por ese camino se encontraron con Nayap. Al sentirlas, él dijo:

- ¿Quién viene apestando como los ojos de Tsuná?- Y es que después de haber jugado con él, su olor se les había quedado en el cuerpo. Las mujeres se pusieron tristes porque ningún hombre las querría después de haber jugado con Tsuná.

Pero Nayap era bien amable. Cuando vio su tristeza les dijo:

- Vayan al río y báñense durante tres días. Si lo hacen así, me casaré con ustedes. $^{26}$

26 En la tradición griega, Afrodita (Venus) recupera la virginidad bañándose en el mar. Véase GRAVES, Robert, Los mitos griegos, L Madrid, Alianza Editorial, 2001, pág. 85.

Bol. Acad. peru. leng. 50(50), 2010 
Pero ellas, avergonzadas, no le hicieron caso. Regresaron por la trocha queriéndose casar con otro hombre, pero no podían hacerlo porque todos las despreciaban al darse cuenta de que habían jugado con Tsuná. ${ }^{27}$

La huito mujer y la achiote mujer lloraron mucho por el desprecio de los hombres. Subieron a una loma alta y, al llegar arriba, la huito dijo a su compañera:

- Vamos a convertirnos en cualquier cosa. ${ }^{28}$ Ya no podemos casarnos con un hombre.

Y allí, paradas en la loma, mirándose se preguntaban en qué podían convertirse.

- ¿Nos convertiremos en una loma alta?- dijo la huito mujer.

- No, si nos convertimos en una loma, para avergonzarnos dirán: "miren qué barriga tan grande"- respondió la achiote.

- ¿Nos convertiremos en un gran pantano?- preguntó de nuevo la huito.

- No, si nos convertimos en un gran pantano, ¿no nos dirían: "estas mujeres que se ensucian tanto son muy mugrientas"?

Después de pensar largo rato, la huito mujer dijo:

- Si nos convertimos en huito y achiote, los jóvenes dirán: "Mamacita, dame huito. Voy a lavarme el pelo con huito. ${ }^{29} \mathrm{Y}$ voy

27 En versiones del mito de otros pueblos del tronco jíbaro, Tsuná se convierte en tsuná japimájmau, una planta apestosa como sus ojos. Véase REGAN, Jaime, «Mito y rito. Una comparación entre algunas imágenes mochicas y jíbaras» en Investigaciones Sociales: Revista del Instituto de Investigaciones Histórico Sociales, n 3, Lima, IIHS, 1999, págs.29-30.

28 Es también característica de la Edad de Oro en todas las tradiciones mitológicas la facilidad de transformación. Véase ELIADE, Mircea, Mitos..., págs. 74-90.

29 La raíz del huito produce una espuma semejante al jabón, y sus frutos un pigmento negro apreciado tanto para resaltar el color del pelo como para pintarse el cuerpo. 
a pintarme con achiote". ${ }^{30} \mathrm{Si}$ dicen esto, ¿No vamos a sentirnos bien? Hermana, convirtámonos en estos árboles.

- Bueno-dijo la achiote mujer-, si tú lo quieres así, levántate en alto y crece.

Y cuando lo dijo, la huito mujer levantándose creció. Y ella, estirando sus brazos, se convirtió en achiote. Las dos tenían sus brazos convertidos en ramas y llenos de los frutos del huito y el achiote.

Entonces, llegaron los animales de monte. Viendo los hermosos colores de los frutos que habían nacido en las ramas de las que fueron mujeres, desearon embellecer se el cuerpo con ellos. Al ver al paujil, la huito dijo:

- Tú has cortado el bambú que me tenía encerrada y me has librado. Voy a darte mis mejores tintes.

Y diciendo esto, extendió sus brazos y los sopló para tener sus frutos maduros. ${ }^{31}$ Entonces, cogiéndolos y raspándolos, sobó la espalda del paujil y la hizo negra. Después, también la achiote mujer tomó sus propios frutos, y haciendo una mezcla con agua pintó el pico del paujil del color rojo más bonito.

La huito mujer hizo otro tanto con la pava del monte, que había mandado llamar al paujil para liberarlas. Restregando sus plumas las tiñó de negro, y su cabeza la hizo blanca pintándola con tiza.

Entonces vino la ardilla y dijo:

- Hacedme bonito a mí también.

30 Los frutos del achiote producen un pigmento rojizo muy apreciado para pintarse el cuerpo.

31 Obsérvese que en la Edad de Oro de los achual los frutos maduran con sólo soplarlos, como veremos también más adelante. 
Pero la huito respondió:

- Aunque así me ruegues, ¿por qué me encerraste con bambú?- Y diciendo esto, arrojó achiote sobre su cuerpo dejándolo rojizo, y le apretó entre sus manos la cabeza, dejándosela ovalada. Y al quejarse la ardilla dijo: tsun tsun tsun, como suena su llamado ahora.

Al mono barrigudo también le dieron hermosos colores ${ }^{32}$ Después arreglaron al trompetero, poniéndole como piernas los carrizos. Le tejieron una camisa de llanchama ${ }^{33}$ y dieron a su cabecita la elegancia que ahora tiene, con huito de color negro brillante.

Después pintaron al tucán, y la achiote, con sus frutos endurecidos, sobándole la cola la hizo colorada; la huito restregó su espalda haciéndola negra. Endureció un hueso de animal en el fuego hasta que se volvió blanco, y así hizo el pico del tucán. Luego deshizo tiza sobre su garganta, y así la dejó blanca.

Distinto trato le dieron al mono araña, que cuando era hombre había despreciado a las hermanas. Preparando una mezcla de huito verde, la vaciaron sobre él, y así quedó marrón. Le golpearon en la frente y en la cara, haciéndole la forma que ahora tiene. La huito,

32 Obsérvese que este animal no había aparecido hasta ahora, como tampoco el tucán, el mono araña (maquisapa) ni el mono aullador (mono coto), que sin embargo son también premiados o castigados por los dos árboles. Esto es debido a que, originariamente, sí participaban del mito, aunque los olvidos los hayan relegado únicamente a esta parte. Sí se explica más adelante el motivo del castigo al mono aullador.

Mono barrigudo: Lagothrix, llamado en la zona mono choro. Véase CABRERA, Ángel y YEPES. José,' Mamíferos sud americanos. Buenos Aires, Ediart, 1960, pág. 107. Mono araña: Ateles, llamado en la zona maquisapa, Ibíd., pág.15. Mono aullador: Alouatta, llamado en la zona mono coto, Ibíd., pág. 106.

33 Llanchama: árbol, manicaria saccifera, con cuya corteza se elaboran colchones y mantas. El motivo de que se le haga al trompetero una camisa de llanchama es dar a entender que se le vistió de corteza. Véase FARR, Ellen; LEUSIINK, Jan; STAFLEU, Frans, Index..., p.1038. 
tirándole de los pulgares se los arrancó. Al mono aullador también lo castigaron arrojándole una mezcla de achiote y dejándolo rojizo. Además, le hicieron tragar un mate que le dio la forma que ahora tiene su garganta, y le agarraron su cabeza y le torcieron el cuello dejándolo jorobado; esta fue su venganza.

Cuando después de un tiempo se encontraron con Nayap ya convertido en pájaro, ${ }^{34}$ en lugar de darle colores, la huito le rompió su ponchito y lo soltó. Es por eso que hoy viste su poncho cortado en dos puntas.

Así hicieron la huito y la achiote con los animales que por el monte estaban.

2. Historia de Nayap y Nuncui, la mujer llegada del cielo, que cuenta la segunda parte de la Edad de Oro.

Nayap, después de que la huito y la achiote se convirtieran en árboles, estaba desconcertado y sin rumbo, y continuamente pensaba: “¿por qué no me caso con una mujer?". Siempre estaba echado fuera de la casa, mirando el cielo, y aunque hubiera gente cerca él permanecía solo. Mirando las estrellas, pensaba "eso que está brillando yo quisiera tenerlo". Y en su soledad cavilaba: "Esos que están por allí, tan bonitos con sus ojitos pequeños en gran cantidad, ¿por qué no caen?"

34 Nayap se convierte en el animal con el que comparte nombre, esto es, una tijera chupa (elanoides forficatus), también conocido como elanio tijereta, especie de milano blanco silueteado en negro, con la cola dividida en dos puntas como la de las golondrinas. Véase PEREYRA, José, Nuestras aves (Tratado de ornitología), Buenos Aires, MOP, 1943, pág.232. Puede que por esta similitud, Gerhard Fast traduce incorrectamente dos palabras de raíz nayap(nayapnasha y nayapnaka) por "golondrina”. Obsérvese que Nayap aparecerá más adelante otra vez con forma de hombre. Esto no es una incongruencia, sino que se debe al hecho de que en la Edad de Oro rige el Gran Tiempo de los mitos, no las leyes del tiempo de este mundo. Véase ELIADE, Mircea, Mitos..., págs. 74-90. 
Entonces, de repente, cayó la mujer Nuncui. Y Nayap se casó con la Nuncui que del cielo había llegado. ${ }^{35}$

Un día, mientras el marido se quedó en la casa sin moverse, ella fue a trabajar al huerto. Aunque se fue sin llevar masato, ${ }^{36}$ tomó un mate $\mathrm{y}$, mascando las hojas tiernas de la yuca, Nuncui regresó a la casa con el masato ya fermentado para dárselo a su marido. ${ }^{37}$ Cuando se lo ofreció a Nayap, él lo tomó con gusto. Nuncui podía preparar masato solamente mirando y soplando la yuca mientras andaba por el huerto. Cuando regresaba a la casa sólo tenía que pelar la yuca; en el breve tiempo de camino el masato había fermentado y estaba ya listo para tomar.

Viviendo así algunos meses, ella salió encinta y una noche dio a luz. Después de tener su niño, lo escondió bajo el emponado. ${ }^{38}$ Sólo de noche lo sacaba para darle el pecho. Se comportaba de esta manera para que nadie tocara ni mirara a su hijo. Quería criarlo allí hasta que supiera andar. ${ }^{39}$ Así, cuando comía patarashca ${ }^{40}$ con

35 Sí mantenemos el nombre de Edad de Oro trasla separación de personas y animales es porque permanece una característica fundamental de este tiempo, como es la facilidad de comunicación y acceso al cielo. También permanece la facilidad para obtener alimentos.

36 El masato es una bebida que se prepara hirviendo yuca, masticándola, escupiéndola en un recipiente y dejando la mezcla fermentar.

37 Obsérvese, frente a la laboriosa elaboración del masato, la facilidad con que es preparado por Nuncui.

38 Emponado: entramado muy duro y resistente de madera de palmera (pona, iriartea exorrhiza) que en las construcciones achual suele utilizarse como piso de las casas, elevado sobre el suelo. Véase FARR, Ellen; LEUSIINK, Jan; STAFLEU, Frans, Index..., pág.876.

39 El sentido material de que Nuncui tenga a su hijo bajo el emponado hasta que sepa andar es, por una parte, la resistencia de éste: si una rama pesada cayera sobre la casa, dado el tipo de construcciones de los achual, podría atravesar el techo pero no el emponado; por otra, si un jaguar con hambre entrase en la casa no podría atrapar a un niño bajo el emponado. Esta costumbre establecida por Nuncui permanece en algunas comunidades más adentradas en la selva.

40 Patarashca: pieza de carne o de pescado que se prepara envuelta con hojas. Véase ZAPATA ACHA, Sergio, Diccionario de gastronomía peruana tradicional, Lima, Universidad de San Martin de Porres, 2006, pág. 531, 
su esposo, ponía las hojas secas y otras cosas bajo el empeñado, para que estuviese mullido.

Cuando el niño apenas empezó a andar, Nayap le dijo a su mujer:

- Ven conmigo a cazar pájaros con la cerbatana. Después vamos a sacar a mi hijo, y vamos a tenerlo ya en la casa.

Y, yéndose los dos, dejaron la casa al cuidado de una cuñada de Nuncui. Antes de marchar, ella le dijo:

- Cuñada, no barras aquí debajo del emponado. Yo barreré cuando vuelva. Pero cuando se marcharon, la cuñada sin hacerle caso empezó a barrer y encontró al niño. Ella se dijo:

- Mi cuñada ha tenido su niño y no nos ha dicho nada, ni nos lo ha mostrado.

Y, cuando estaba tratando de tomarlo en sus brazos y darle el pecho, el niño le mordió los senos con los dientes que ya tenía.

- ¿Qué es esto? - se dijo ella, dejando a la criatura - ¿Este niño qué será? ¿Es como nosotros? ¿Tal vez es un dios? ¿Quién será esta Nuncui?

Entonces empezaron a caer rayos uno tras otro. En la lejanía, Nuncui dijo:

- Han matado a mi hijo.

Y ella y su marido, que se preguntaba por qué caían tantos rayos, regresaron a la casa. Llegaron en plena lluvia, y el niño ya estaba muerto.

Nuncui gritó y lloró por su hijo, y le dijo a su marido: 
-¿Por qué han hecho sufrir a mi hijo? Yo he dicho que cuando una mujer tiene un niño, deben ponerlo bajo el emponado, sacándolo sólo su madre para darle el pecho de noche, y poniéndolo allí otra vez. Nosotras las mujeres nuncui hacemos madurar la yuca con sólo soplarla, y hacemos madurar los plátanos con sólo mirarlos. Yo hice que ustedes también vivan así para no tener que afanarse cocinando y trabajando en los huertos, yo hice que sus niños vivan bien sin enfermarse. Pero han matado a mi hijo. Por haberme tratado así, ahora me voy al cielo. Tú quédate, Nayap.

- No- respondió él llorando, porque amaba a su mujer.

-Entonces, agarra mi cabeza- dijo, y luego se volvió hacia la gente para maldecirla. - Ustedes antes trabajaban soplando no más; ahora no va a ser así. No podrán cocinar y desyerbar los huertos sin esfuerzo, pasando el tiempo entre conversación y risas, porque ustedes han matado a mi hijo.

Y con estas palabras se fue al cielo. Nayap también se fue, convirtiéndose para siempre en tijera chupa -elanio tijereta-. Como los pájaros que vuelan por acá, así es ahora Nayap.

Por todo esto, ahora tenemos que trabajar. Los que viven por aquí, todos cuentan la historia de la Nuncui mujer.

3. Historia del hombre que se casó con una sirena, que cuenta la expulsión del Paraíso, el Diluvio Universal y el origen de la gente de esta tierra.

Un hombre que pescaba vio una anaconda enredada en un espinar, y librándola la devolvió al río. En la noche, una bonita mujer llegó a su casa y le dijo:

- Mi papá te manda decir que vengas.

Sin embargo, el hombre no quiso ir. Más tarde ella le repitió la invitación, y cuando por segunda vez él se negó, la mujer le dijo: 
- Nosotros vivimos igual que ustedes.

Entonces él, aceptando, se fue con la mujer. Cuando llegaron al río, ella le dijo:

-Agárrate a mi cabeza.

Y así, buceando en el río, llegaron rápidamente a un pueblo donde había muchas casas. La gente vivía en las aguas sin ahogarse, como nosotros vivimos en tierra. Por todas partes había peces, tantos que allí los llamaban cucarachas. El pueblo era parecido a los que ahora tenemos, porque los habitantes del río enseñaron al hombre cómo construir su casa. Pero allí, el amo de la casa no se sentaba sobre su taburete de honor, sino encima de una tortuga charapa; a los visitantes se les invitaba a acomodarse no en los bancos de cortesía, sino encima de caimanes negros. ${ }^{41}$

Allí le contaron al hombre que la joven que había salvado era una sirena, y al salir a tierra a pleno día se convertía en anaconda.

- Como has tenido compasión de esta mujer, cásate con ella- le dijeron.

Y él, aceptando, se casó con la mujer. Después de pasar largo tiempo viviendo en el pueblo bajo el río, otra vez el hombre regresó a su casa. Llegó de noche y durmió con su mujer, que al amanecer se convirtió en anaconda. Entonces él, envolviendo la serpiente con telas, la puso en un canastón. Cuando llegaba la noche, ella se convertía de nuevo en mujer.

41 Tortuga charapa: podocnemis expansa. Caimán negro: paleosuchus trigonatus. Hemos añadido este párrafo para dar una idea más completa sobre los tsunki de la que ofrece el texto original, que omite aquello que para la cultura achual es sabido; hemos elaborado la ampliación a partir de la información que se aporta en DESCOLA, Philippe, La selva culta. Simbolismo y praxis en la ecología de los Achuar. Quito, Abya-Yala/ IFEA, 1988, págs 176-177 y 376-381, respectivamente. 
El hombre todas las noches dormía con su mujer y en las mañanas, antes de irse a bañar, ponía la anaconda en su canastón. Saliendo de su casa un día, les dijo a su madre, sus hermanas y su abuela que no tocasen aquella cesta. Sin embargo su madre, queriendo saber por qué decía aquello su hijo, abrió el canastón y vio la anaconda.

- ¡Qué atroz! — dijo, y la golpeó con un palo.

Pero la anaconda, sin morirse, cayó al río. Entonces comenzó a llover con fuerza, y empezó a soplar el viento. El hombre llegó corriendo y dijo:

- ¿No oyeron lo que les había dicho? Ustedes van a sufrir. ${ }^{42}$

Y cuando hubo dicho esto, después de poco tiempo, empezó a crecer el río. Aunque no era todavía la época de lluvias, cuando el aguacero dura varios días y los ríos suben su nivel, no paraba la tromba de agua. Con ella vino la creciente, más alta y con más fuerza de lo que nadie recordaba. Superó la marca de las crecientes más abundantes, y aún siguió subiendo. Aunque era pleno día también bajó el Sol. Así empezó la más alta creciente y la noche más larga.

El río inundó las casas y, aunque la gente se subió a los techos, la creciente los cubrió. También se inundó todo el monte. Sin embargo, en una loma, un hombre se subió a un huito.

Cuando la mujer que había sido golpeada lo vio, dijo:

- A este también lo mataré, haciendo que el agua cubra la loma.

42 En la tradición mitológica griega, Atenea entrega a una mujer una cesta en la que se encuentra Erictión, en parte niño y en parte serpiente, con advertencia de no abrirla. Cuando la mujer y sus hijas abren la cesta son castigadas con la locura, y mueren al caer desde la Acrópolis. Véase APOLODORO, Biblioteca mitológica, Madrid, Alianza Editorial, 2004. III, 14, 6. También GRAVES, Robert, Los mitos griegos. I Madrid, Alianza Editorial, 2001.pag.126. 
Pero el hombre que se había casado con ella, y que al empezar la creciente se había ido a vivir con las sirenas, dijo:

- No, él que se quede con vida- y así lo hicieron. ${ }^{43}$

El hombre que estaba en lo alto del huito, como era de noche y no podía ver si el agua había bajado, para saberlo tomó un fruto y lo arrojó, y al caer sonó como si entrase en aguas profundas. Así es que se quedó todavía en el árbol. Muchos días pasaron, aunque siempre era de noche. Cuando estaba hambriento, algo como un hombre le daba sachapapa cocida, también plátano cocido con carne de chancho zajino. ${ }^{44}$ Otra vez volvió a tomar un fruto del huito y arrojarlo, y esta vez sonó como si el agua estuviese más baja.

El hombre se preguntaba cuándo amanecería. Era mucho el tiempo que había pasado allí solo, en lo alto del huito. En un sueño se le presentó un hombre y le dijo: "No te preocupes, pronto amanecerá". ${ }^{45}$ Todavía pasó cierto tiempo hasta que el gavilán empezó a cantar con los primeros rayos de luz. Entonces el hombre arrojó otro fruto del huito, y esta vez sonó al golpear la tierra. Después, rápidamente amaneció. ${ }^{46}$

Cuando había amanecido, el hombre bajó a la tierra. Y bajando encontró solamente silencio en la casa, porque todos se habían ahogado. Él se quedó allí solo, y se fue al monte a matar animales. Cuando regresó, encontró en la casa maíz mascado y listo para comer.

43 En la tradición de la India, un hombre salva a un pequeño pez de la muerte y lo alimenta; con el tiempo, el pez se convierte en un monstruo del mar que, llegado el Diluvio, salva al hombre. Véase EGGELING, Julius, The Satapatha Brahmana, Oxford, Clarendon Press, 1882, págs. 216-218.

44 Chancho sajino, también zajino: cerdo negro de la selva.

45 Es posible que quien cuida del hombre sea el marido de la sirena, aunque el texto no lo refiere.

46 Obsérvese la relación con las historias del Diluvio de otras tradiciones como la sumeria, la bíblica, la griega, las de otros pueblos indígenas. 
-¿Quién está aquí?- llamaba y llamaba, pero nadie respondía.

Entonces estuvo pensando, y al día siguiente dijo en voz alta "Me voy a buscar comida", pero se escondió junto a una mata de plátano para ver qué ocurría.

Llegaron entonces la lora de las alas coloradas que se llama tincu, la lora de frente amarilla, la lora chicuari y la uchpa lora, ${ }^{47}$ riendo y gritando. Y cuando llegaron a la casa, se convirtieron en mujeres. El hombre, viendo esto, pensó que podía agarrar a las loras y hacerlas sus esposas.

Así, el hombre las acechó mientras preparaban la comida que luego, creyendo que él no las veía, le dejaban. Un día en que preparaban masato, agarró a la lora de las alas coloradas, la tincu. Se casó con ella en el río Corrientes, y las personas que vienen de los hijos que tuvieron son algunas feas, otras lindas.

Otro día en que las loras desgranaban maíz, el hombre agarró a la lora de la frente amarilla, que era la más bonita. Y se casó con ella en el río Huasaga, y la gente que viene de los hijos que tuvieron ha aumentado mucho en número.

Después, acechando desde una trocha el hombre consiguió agarrar a la uchpa lora y a la chicuari, y se casó con ellas en otro lugar del río Corrientes. Los que vienen de la uchpa lora convertida en mujer son gente alta de piel más blanca, y los que nacieron de la lora chicuari mujer son bajitos y de piel oscura. $^{48}$

47 Estas loras son diversas especies del género Amazona.Véase Enciclopedia Salvat... tomo 5, pág. 291.

48 Cada una de estas historias de matrimonio es contada sólo por la comunidad que se reclama proveniente de cada una de las distintas uniones: los que provienen de la lora de alas coloradas afirman que el hombre sólo se casó con ella, etc. En la actualidad los achual, como su antepasado mítico, siguen practicando la poligamia. 
Análisis

Los mitos del paraíso comparten en todas las tradiciones una serie de características: en la Edad de Oro se disfruta de inmortalidad, libertad, espontaneidad; posibilidad de ascender al cielo y encuentro fácil con los dioses; amistad con los animales y conocimiento de su lengua. Esta situación inicial se pierde, produciéndose una caída del ser humano por un pecado o error, que le lleva al mundo y la sociedad en donde rigen la muerte, las leyes físicas y temporales, donde existen las jerarquías y el trabajo. En los mitos de los achual vemos una expresión particular de estas características generales. En primer lugar, es reseñable el hecho de que la pérdida de la condición edénica no se da de golpe, sino a través de tres errores que van dando paso a tres momentos distintos aunque paradisíacos, cada uno de ellos degradado respecto del anterior, hasta llegar a la época actual. Veamos este desarrollo.

La primera parte de la Edad de Oro (que en este estudio corresponde al relato "Historia de Nayap y las mujeres árbol") cuenta en la expresión achual con todas las características paradisíacas; aunque no todas aparezcan explícitamente, están implícitas o aparecen en los relatos siguientes, lo que implica que en el primero ya existen. Así, la inmortalidad se deduce de que las dos mujeres, al abandonar el mundo humano, no mueren, sino que se transforman en árboles, y los castigos que infligen a sus maltratadores son, exclusivamente, cambios en el color o la forma que tendrán como animales, en ningún caso la muerte. Asimismo, el hecho de que las dos mujeres puedan recuperar la virginidad bañándose en el río implica que en esta etapa no hay estados físicos permanentes, característica de una sociedad de inmortales. La libertad y la espontaneidad vienen dadas por la facilidad para conseguir el alimento a través de su multiplicación de manera mágica, (lo que entronca con la conocida idea de que el trabajo no existe en el paraíso) así como la posibilidad de cambiar de forma y naturaleza a elección. La posibilidad de acceso al cielo y el encuentro fácil con los dioses sólo se explícita en la segunda parte de la Edad de Oro (que corresponde al relato "Historia de Nayap y Nuncui"), pero, dado que ésta es una etapa degradada con respecto a la primera, lo que implica que en ella se dan menos características paradisíacas que en su precedente, 
se entiende que estas posibilidades provienen de la etapa primera. La amistad con los animales y el conocimiento de su lengua tienen en los mitos achual la interesante expresión de que personas, animales y plantas comparten en el inicio una misma naturaleza, interactuando como miembros de una misma especie y sociedad.

La caída que lleva al mundo a entrar en la segunda parte de la Edad de Oro -que tiene, como ya hemos señalado, menos características paradisíacas- se produce a raíz del engaño de Tsuná a las dos mujeres y el desprecio con que después son tratadas por los varones. El resultado es:

la aparición de la muerte;

la aparición del trabajo - que será conjurada por Nuncui-, y la pérdida de la capacidad de comunicación con los animales. Este hecho se produce en el momento en que la huito castiga a la ardilla, que al intentar quejarse emite no palabras, sino el sonido característico de este animal, quedando así establecida la separación definitiva entre el lenguaje de los animales y de los seres humanos

La segunda parte de la Edad de Oro (el relato "Historia de Nayap y Nuncui") cuenta, en origen, con las carácterísticas paradisíacas de posibilidad de ascender al cielo y encuentro fácil con los dioses, y está marcada por la llegada de un ser venido del mundo superior, la mujer Nuncui, quien con su presencia reinstaura precariamente la inmortalidad, la libertad y la espontaneidad y establece las normas de crianza de los hijos que hemos visto. En esta etapa, si bien ya ha aparecido la muerte, la presencia de Nuncui mantiene a los seres humanos a salvo de las enfermedades (lo que se explícita en el discurso de maldición, antes de su marcha) y sus consecuencias. La libertad y la espontaneidad son ahora relativas, puesto que sólo se pueden desafiar las leyes físicas con la ayuda de Nuncui (para marcharse con ella convirtiéndose en pájaro, Nayap necesita su asistencia); el trabajo, no obstante, sigue sin ser una obligación debido a las capacidades mágicas que la mujer da a los seres humanos. La posibilidad de acceso al cielo es, una vez más, propiciada únicamente por Nuncui, mientras que el encuentro fácil con los dioses está expresado por el hecho de que sólo la plegaria de Nayap dé lugar a 
la llegada de esta mujer sobrehumana. La caída que conduce a la tercera parte de la Edad de Oro se produce por la desobediencia del mandato de un ser sobrenatural, Nuncui. Cuando su cuñada descubre al niño, el castigo llega en primer lugar desde el cielo, matando al hijo de la pareja protagonista (y, por tanto, reinstaurando la muerte entre los humanos); más tarde, Nuncui maldice a la comunidad desobediente, devolviendo a la humanidad los males que había conjurado, esto es, la enfermedad y el trabajo.$^{49}$ La facilidad de acceso al cielo, la libertad y la espontaneidad, que Nuncui había propiciado, se marchan con ella.

La tercera parte de la Edad de Oro (el principio del relato "Historia del hombre que se casó con una sirena") cuenta únicamente con tres características paradisíacas: la libertad y la espontaneidad pero ya degradadas, una libertad y espontaneidad sólo conseguidas a través de la tercera característica que se mantiene, la facilidad de contacto con seres sobrenaturales. Tras haber salvado a la anaconda, el hombre protagonista del principio del relato sigue a la mujer que aparece en su casa (que es en realidad la anaconda) hasta un pueblo bajo las aguas, la toma por esposa y vive durante un tiempo junto a los seres habitantes del río, los tsunki. Regresa después a su casa en tierra junto a su esposa, quien por el día se convierte en serpiente, dando orden de que no se abra el canastón donde está guardada en las horas de luz. Al ser desobedecida esta orden, se provoca la expulsión del paraíso y el comienzo del Diluvio Universal.

Como vemos, la caída que produce que el ser humano haya llegado a su situación actual es resultado de la desobediencia contra un hombre elegido por los seres sobrenaturales. Por efecto de esta caída, el hombre no podrá comportarse con libertad y espontaneidad, y el contacto con los dioses será difícil, reservado a los elegidos. Es importante señalar que la elección divina se manifiesta en la cultura achual a través de la visita sobrenatural de una mujer tsunki, al igual que ocurre con el hombre del

49 En la actualidad, Nuncui es considerada como una divinidad benefactora de la agricultura. Véase DESCOLA, Philippe, «Las cosmologías de los indios de la Amazonia», en Zainak. Cuadernos de antropología-etnografía, n 17, San Sebastián, SEV, 1998, págs. 219-227. 
mito. ${ }^{50}$ La visita da lugar a que el elegido pueda comenzar su aprendizaje para llegar a ser chamán, que es el encargado de restaurar, durante la liturgia, el paraíso en la tierra $^{51}$.

Los mitos que hemos visto corresponden antropológicamente a un grupo humano en el que permanecen algunos de los conflictos psicológicos producidos por el paso de una sociedad nómada de cazadores-recolectores de estructura matrilineal a una sociedad sedentaria de agricultores-cazadores de organización patriarcal. Estos conflictos se expresan de manera directa en las narraciones estudiadas, dado que el sistema sociosimbólico triunfador, el patriarcal en este caso, sitúa su propio origen en el Gran Tiempo y, así, vemos continuas referencias al poder masculino entreveradas con reminiscencias matriarcales.

No obstante, también encontramos referencias simbólicas de otro tipo, relacionadas con la narratividad y la lógica interna del relato. Merece un breve estudio, para empezar, el comportamiento y castigo del hombre que será ardilla. Como hemos visto, promete matrimonio a las dos mujeres y les encarga cosechar su maíz, sin advertirles de que se trata de plantas mágicas cuyo fruto se multiplica al entrar en el monte. Debido a esto se llevan todas las mazorcas, lo que provoca el enfado injustificado de la ardilla y el encierro de las mujeres.

Claude Lévi- Strauss ya demostró ${ }^{52}$ la estrecha relación existente, dentro de las expresiones míticas, entre el lenguaje, el sexo y el matrimonio y la fertilidad de la tierra. Así, observa que en el relato de Edipo la resolución del enigma planteado por la Esfinge se relaciona con el incesto y la peste que cae sobre Tebas. En efecto, la respuesta al enigma, que por definición es una pregunta sin respuesta, acerca aquello que siempre debió permanecer separado (pregunta y respuesta, Edipo y Yocasta) produciendo un verano

50 Véase TAYLOR, Anne Christine, «Des fantômes stupéfiants. Language et croyance dans la pensée achuar », en L'Homme, volumen 33, n 126-128, Paris, EHESS, 1993, págs. 437-439.

51 Véase ELIADE, Mircea, Mitos...págs 81-82.

52 LEVI-STRAUSS, Claude, Antropología estructural. Mito, sociedad, humanidades. Salamanca, Siglo XXI, 2009, págs. 23-28. 
perpetuo que quema la tierra. Por otro lado, advierte que en el relato del hallazgo del Grial por Parsifal en los ciclos artúricos, el caballero no es capaz de formular una pregunta que ya se le había indicado, tras la cual se le daría una respuesta ritual y la copa de la vida le sería entregada. El silencio ante una situación comunicacional prefijada se relaciona con la impotencia sexual y, de hecho, produce en el relato un invierno perpetuo en Bretaña.

Vemos, de este modo, cómo en todas las culturas - no únicamente las griegas y célticas- el lenguaje es símbolo por excelencia de la vida social. Dado que las relaciones entre comunidades humanas se establecen primeramente a través de la unión de parejas de distintas familias, lenguaje y pareja estarán íntimamente unidos en los relatos míticos por ser el fundamento de la sociedad, (para la vida en comunidad se espera que la palabra sea sincera y la unión matrimonial, no espuria) y este conjunto estará unido por una relación interna a la fertilidad de la tierra, fundamento de la vida física. Así, la resolución del enigma, lenguaje en exceso, se relaciona con el incesto y un perpetuo verano quemante; el silencio ante una situación prefijada, falta de lenguaje, se une a la impotencia y a un perpetuo invierno agotador.

Aplicando este principio al relato que estudiamos, el silencio de la ardilla, el no hacer una advertencia que debió haber sido pronunciada, se relaciona con que no se cumpla la promesa de matrimonio y con el agotamiento del huerto mágico que proveía eternamente de maíz. La falta de lenguaje, ahora, se une a la no realización del matrimonio ${ }^{53}$-lo que implica falta de relación sexual- y a una destrucción de la fertilidad paradisíaca. Es por esto que, siguiendo la lógica interna del texto, la ardilla, causante de la desaparición de una característica de la Edad de Oro, sea castigada al tomar forma animal siendo la primera especie que pierde el lenguaje, estableciendo de este modo la supresión de otra característica paradisíaca, la facilidad de comunicación entre animales y humanos.

53 Entiéndase aquí "matrimonio" de manera amplia, como "relación pública de pareja estable", dado que en la etapa paradisíaca, presocial por definición, no se han instituido todavía los ritos sociales.

Bol. Acad. peru. leng. 50(50), 2010 
Tras ser libradas de su prisión, se produce el encuentro de las mujeres con Nayap y el engaño de Tsuná. Vemos, como ejemplo de referencias simbólocas patriarcales, que los dos hombres quieren llevar a las dos mujeres-árbol (que, no en vano, aparecen solas en el relato) a su propia casa, reflejando el régimen patrilocal. Además, cuando se ha producido el engaño las mujeres sufren desprecio por haber perdido su virginidad, hecho que no es habitual ni en los sistemas matriarcales ni, por cierto, en la mayoría de pueblos indígenas de la cabecera del Amazonas. ${ }^{54}$ No obstante, el recuerdo de la sociedad "matriarcal" permanece expresado a través del castigo que las mujeres-árbol infligen a sus maltratadores (ya se ha comentado el de la ardilla), así como, más adelante, en el hecho de que el ser llegado del cielo a reinstaurar parcialmente el paraíso sea femenino y en que hoy Nuncui sea una de las deidades principales del panteón achual.

El episodio de los castigos y premios de las mujeres-árbol a los distintos seres que se convertirán en los animales del bosque remite a varias ideas importantes: una, el ya citado poder de la mujer, probable reminiscencia de un viejo sistema de matrilinealidad. Dos, la necesidad de equilibrio: nadie que cometa una injusticia debe quedar impune; nadie que actúe bien debe quedar sin premio; nadie que haya sufrido ha de permanecer sin reparación. Y tres, la aparición de los animales y plantas. Este tipo de relatos son abundantes en todo el Amazonas ${ }^{55}$ y expresan al tiempo un mito de origen y un mito etiológico animal.

La aparición de Nuncui expresa la idea ya señalada de la necesidad de equilibrio: Nayap, que se ha quedado solo sin ser culpable de la marcha de las mujeres recibe un premio individual y colectivo: por una parte, él tendrá una compañera; por otro, se reinstauran algunas características paradisíacas que se habían perdido por la crueldad de la ardilla, de Tsuná y de otros animales y se recuperan por la plegaria de un hombre que actuó

54 Véase CIEZA DE LEÓN, Pedro, La crónica del Perú, Buenos Aires, Espasa-Calpe, 1945, págs. $110-173$.

55 Véase LÉVI-STRAUSS, Claude, Mitológicas I. Lo crudo y lo cocido. México, FCE, 1972, págs. 22-306. 
con justicia. El error que produce la muerte del hijo de Nuncui y la marcha de ella es cometido ahora por una mujer - simbolismo patriarcal: tanto este error como el origen del Diluvio se producen por la desobediencia femenina, como la desobediencia de Eva entre los hebreos, como la de Pandora entre los griegos, causantes de distintas desgracias - y expresa la enorme importancia, en un entorno tan lleno de peligros como la selva, de prestar especial atención en el cuidado de los menores.

Dado que la marcha de Nuncui y la transformación de Nayap se han comentado anteriormente, avanzamos hasta el encuentro del hombre y la anaconda. El premio a una persona que salva a un ser aparentemente humilde o desprotegido, que es en realidad poseedor de un poder superior, se conoce en todas las culturas, en especial en los mitos cosmogónicos hindúes (ver nota 47). La originalidad reside aquí, por una parte, en que este ser pertenezca al pueblo de los tsunki, espíritus habitantes de las aguas conocidos desde el Amazonas a los Andes ${ }^{56} \mathrm{y}$, por otra, en que el premio consista en darle al hombre la posibilidad de vivir como ellos, trascendiendo su naturaleza humana de un modo similar al de Nayap.

La mujer anaconda, por su parte, expresa un simbolismo dual. Su imagen de serpiente ${ }^{57}$ la relaciona por un lado con la sabiduría, y de ahí también su condición de tsunki, que la hace sobrenatural; y por otro, con el caos, de ahí que sea la creadora del Diluvio. Tiene, así, un doble carácter: benéfico, al ofrecer al hombre que la ha salvado la posibilidad de vivir bajo las aguas antes y después del Diluvio; vengativo, cuando inicia éste y cuando está a punto de exterminar a toda la raza humana, cosa que no hace por la intervención de su marido.

Abrimos un inciso para señalar que la salvación del hombre es una de las partes más originales y hermosas en lo simbólico de los mitos paradisíacos de la cultura achual. Llegada la subida de las aguas, que

56 Los tsunki son llamados yacurunas en la tradición quechua.

57 Para la simbologia dual de la serpiente, véase BECKER, Udo, Enciclopedia de símbolos, Barcelona, Swing, 2008, págs. 378-386, y DE JONNÉS, Moreau, Los tiempos mitológicos, Barcelona, Edicomunicación, 1998, págs. 46-51. 
simboliza la destrucción de las formas conocidas para regresar a la materia informe primordial y que sea creada, desde ella, un mundo renovado en lo material y lo social, el único superviviente y refundador de la humanidad se sube, para salvarse, a un huito (recordemos: una de las mujeres-árbol del primer texto). Y he aquí la originalidad y la belleza: una mujer engañada y despreciada se convierte en salvadora de la humanidad y en axis mundi, centro del mundo que será utilizado no sólo para el renacimiento de la especie humana al tiempo cosmológico actual, sino también para acceder al paraíso. En efecto, a los chamanes achual, cuando ofician su liturgia, se les aparece un árbol de huito por el que ascienden, reinstaurándolo, al paraíso. ${ }^{58}$

Una vez iniciado el Diluvio y salvado el hombre que repoblará la tierra, éste es alimentado y alentado por un ser cuya naturaleza no se explícita, aunque bien pudiera ser el marido de la anaconda. El hecho de que la revelación del retorno de las aguas a una situación que permite la vida le llegue al hombre mientras duerme habla bien a las claras de la función del sueño como elemento adivinatorio en la cultura achual.

Es interesante la aparición de los pájaros que se convierten en mujeres. La imagen del elemento masculino solitario y en tierra, y el femenino en un nivel celeste está extendida por todo el Amazonas ${ }^{59}$ y expresa una disyuntiva para la Humanidad (ahora representada sólo por varones) entre romper su último vínculo con los cielosdonde, desde ese momento, sólo podrán acceder los elegidos- o condenarse a la desaparición por no poseer mujeres con las que reproducirse, dilema que siempre se resuelve obligando al elemento femenino a permanecer en la tierra, lo que a la vez implica, como veremos, la aceptación de los errores

$58 \quad$ El árbol como centro del mundo es un símbolo Que se crea en las sociedades humanas una vez iniciado el proceso de sedentarización y que en muchos casos ha permanecido en las culturas urbanas, sobre todo orientales. Véase ELIADE, Mircea, The myth ofthe eternal return, Princeton, Princeton University Press, 1974, págs.12-17.

59 Véase esta imagen en el pueblo indígena peruano de los cañaris en SPENCE, Lewis, The Myths of Mexico and Peru, Nueva York, Dover publications, 1994 [1913], págs 318- 319; y una imagen similar entre los pueblos brasileños de los toba-pilaga y los matako en LÉVISTRAUSS, Claude, Mitológicas I... págs. 116-122. 
cometidos por los varones precedentes y la renuncia a la cercanía celeste, última característic paradisíaca.

En la expresión achual que estamos estudiando, las mujeres-pájaro se relacionan en un sistema de oposiciones con los otros personajes principales femeninos que han aparecido. ${ }^{60}$ Así, la huito y la achiote comienzan siendo mujeres y se transforman en árboles, parte del mundo natural; Nuncui empieza siendo estrella y vuelve a serlo; la sirena empieza siendo un espíritu con dos manifestaciones corpóreas (mujer y serpiente) y vuelve a serlo; las mujeres-pájaro empiezan siendo animales, parte del mundo natural, y se convierten en seres humanos.

\begin{tabular}{|c|c|c|}
\hline Personaje & Estado inicial & Estado final \\
\hline Huito y achiote & Mujeres & Árboles \\
\hline Nuncui & Estrella & Estrella \\
\hline Sirena & Espíritu & Espíritu \\
\hline Mujeres-pájaro & Pájaros & Mujeres \\
\hline
\end{tabular}

En este sistema opositivo se da una transición en la cual los personajes principales femeninos comienzan siendo humanos y, por tanto accesibles; dejan de serlo por un error masculino; los siguientes personajes principales femeninos comienzan siendo seres sobrenaturales inaccesibles, dejan de serlo por un buen comportamiento masculino y por un error masculino vuelven a serlo; los últimos personajes principales femeninos empiezan siendo pájaros, por lo tanto inaccesibles (en lo que a establecimiento de relaciones de pareja se refiere) y se convierten en accesibles por la renuncia de los varones al contacto con el mundo celeste, última característica paradisíaca. Veámoslo gráficamente:

60 «Los símbolos no tienen un significado intrínseco e invariable, no son autónomos con respecto al contexto. Su significado es ante todo de posición. » Ibid., pág. 62. 


\begin{tabular}{|c|c|c|}
\hline Personaje & Accesible por & Inaccesible por \\
\hline Huito y achiote & - & Crueldad-castigo \\
\hline Nuncui & $\begin{array}{c}\text { Comportamiento de } \\
\text { Napay-premio }\end{array}$ & $\begin{array}{l}\text { Descuido en la crianza } \\
\text { de los menores-castigo }\end{array}$ \\
\hline Sirena & $\begin{array}{c}\text { Comportamiento del } \\
\text { hombre salvador-premio }\end{array}$ & $\begin{array}{l}\text { Desobediencia a un } \\
\text { elegido-castigo }\end{array}$ \\
\hline Mujeres-pájaro & Pájaros & - \\
\hline
\end{tabular}

En el final del relato es necesario comentar todavía que la imagen de las mujeres procedentes de una forma originaria de loras representa un mito etiológico -los hombres achuar siguen considerando que las mujeres, como las loras, son proclives a la algarabía y las risas- del mismo modo que el hecho de que el hombre aceche y capture a las mujeres en la selva - hoy día, el lugar reservado a las relaciones sexuales entre parejas casadas no es la casa, sino la selva. ${ }^{61}$ Es importante también señalar que la renuncia al Paraíso se produce cuando el ser humano toma conciencia de sus propios errores y de la verdad de su naturaleza y, asumiéndolos, inicia al tiempo su madurez psicológica y su andadura por el tiempo actual. La inocencia primera, la completa beatitud, da paso a la responsabilidad y ésta a la preocupación por todo cuanto la pérdida de la condición edénica ha traído: la esclavitud a los condicionamientos físicos, el trabajo y la muerte.

Para finalizar, hemos de volver al comienzo de nuestro estudio y preguntarnos, a la luz de estos mitos y su interpretación, qué imagen tiene y transmite de sí mismo el pueblo achual. Como hemos visto, se nos presenta nostálgico de un mundo antes de la crueldad y de la mentira, antes de las obligaciones sociales y el trabajo, antes de la desconfianza y la astucia, antes de la enfremedad y la muerte. Se presenta nostálgico de un mundo en el que el ser humano es libre en su más amplio sentido, libre frente a las leyes físicas, ingenuo, inmortal. El habitante del paraíso se nos presenta, en definitiva, nostálgico del paraíso.

61 DESCOLA, Philippe, La selva culta..., pág.183. 


\section{BIBLIOGRAFIA}

ANGLERIA, Pedro Mártir de. Décadas del Nuevo Mundo. México, Secretaría de Educación Pública, 1964 (2 tomos).

APOLODORO. Biblioteca mitológica, Madrid, Alianza Editorial, 2004.

ARNALOT, José. Lo que los achuar me han enseñado, Quito, Abya-Yala, 2007.

BECKER, Udo. Enciclopedia de símbolos, Barcelona, Swing, 2008.

BRACK EGG, Antonio y YANEZ, Carlos (Coordinadores). Amazonia peruana: Comunidades indígenas, conocimientos y tierras tituladas. Atlas y base de datos. GEF / PNUD / ONUPS. Edición en CD-ROM, 1998.

CHUMAP PIRISAN, Mariano. «Nuva nuvatkatin (el matrimonio)», en FAST, Gerhard, Cuentos folklóricos de los achual, Lima, ILV, 1978, págs. 124-133.

CIEZA DE LEÓN, Pedro. La crónica del Perú, Buenos Aires, Espasa-Calpe, 1945.

COLÓN, Cristóbal. La carta de Colón anunciando el Descubrimiento. Barcelona, Linkgua, 2004.

CRO, Stelio. «Las fuentes clásicas de la utopía moderna: el Buen Salvaje y las Islas Felices en la historiografía indiana». En Anales de Literatura Iberoamericana, ${ }^{\circ} 6,1977$, págs. 39-51.

DESCOLA, Philippe. La selva culta. Simbolismo y praxis en la ecología de los Achuar. Quito, Abya-Yala/IFEA, 1988.

. «Las cosmologías de los indios de la Amazonia», en Zainak. Cuadernos de antropología-etnografía, $\mathrm{n}^{\circ}$ 17, San Sebastián, SEV, 1998, págs. 219-227. 
DEJONNÉS, Moreau. Los tiempos mitológicos, Barcelona, Edicomunicación, 1998.

EGGELING, Julias. The Satapatha Brahmana, Oxford, Clarendon Press, 1882.

Enciclopedia Salvat de las Ciencias. Salvat, Pamplona, 1968 (6 tomos).

ELIADE, Mircea. Mitos, sueños y misterios, Madrid, Kairós, 2001.

. The myth of the eternal retum, Princeton, Princeton University Press, 1974.

FARR, Ellen; LEUSIINK, Jan; STAFLEU, Frans. Index Nominorum Genicorum (Plantarum), Utrecht, Bohn, Scheltema \& Holkema, 1979.

FAST, Gerhard, Cuentos folklóricos de los achual, Lima, ILV, 1978

. Estructura de la narración en el achual, Lima, ILV, 1975

. Sistema fonológico del idioma achual (a); Palabras onomatopéyicas en achual (b), Lima, ILV, 1975.

. Diccionario achuar-shiwiar castellano, Lima, ILV, 1996.

. y FAST, Ruby. Introducción al idioma achuar, Lima, ILV, 1981.

GALEANO, Eduardo. Memoria del fuego I: Los nacimientos. Madrid, Siglo Veintiuno Editores, 2003 [1982].

GRAVES, Robert. Los mitos griegos, Madrid, Alianza Editorial, 2001 (2 tomos). 
HESÍODO. Teogonia. Trabajos y días. Escudo. Certamen. Madrid, Alianza Editorial, 2001.

HOMERO. Odisea, Barcelona, Círculo de Lectores, 1981.

INSTITUTO LINGÜÍSTICO DE VERANO. Guía de lengua quechua para castellano-hablantes, Lima, ILV, 2007.

JAWKAY, Marta. Listas comparativas de palabras usuales en idiomas vernáculos de la selva, Lima, ILV, 1975.

LAS CASAS, Fray Bartolomé de. Historia de las Indias. Selección, edición y notas de José Miguel Martínez Torrejón, Alicante, Biblioteca Virtual Miguel de Cervantes, 2006 (edición digital).

LÉVLSTRAUSS, Claude. Antropología estructural. Mito, sociedad, humanidades. Salamanca, Siglo XXI, 2009.

. Mitológicas I. Lo crudo y lo cocido. México, FCE, 1972.

MONTAIGNE, Michel de. Les Essais de Michel de Montaigne. Edición de Pierre Villey, París, 1930.

MURDOCK, George Peter. «Ethnographic Atlas: a summary», en Ethnology, nº6, volumen 2, University of Pittsburgh, 1967, págs. 108-236.

POLÍA, Mario. La sangre del cóndor, Lima, FECP, 2001.

REGAN, Jaime. «Mito y rito. Una comparación entre algunas imágenes mochicas y jíbaras», en Investigaciones sociales: revista del Instituto de Investigaciones Histórico Sociales, $\mathrm{n}^{\circ}$ 3, Lima, IIHS, 1999, págs 27 46.

SPENCE, Lewis. The Myths of México and Perú, Nueva York, Dover publications, 1994 [1913]. 
TAYLOR, Anne Christine. «Des fantômes stupéfiants. Language et croyance dans la pensée achuar», en L 'homme, volumen 33, n 126-128, París, EHESS, 1993, págs. 429-447.

WIPIO, Gerardo, PAATI, Alejandro y JAKWAY, Marta. Diccionario aguarunacastellano, Lima, ILV, 2000.

ZAPATA ACHA, Sergio. Diccionario de gastronomía peruana tradicional, Lima, Universidad de San Martín de Porres, 2006.

\section{Correspondencia:}

Héctor Gómez Navarro

Universidad de Oviedo

Correo electrónico: hector@hesperya.com 